\title{
Health service 'input' and mortality 'output' in developed countries
}

\author{
A. L. COCHRANE \\ From Rhoose Farm House, Rhoose, South Glamorgan
}

\author{
A. S. St. LEGER AND F. MOORE \\ From the MRC Epidemiology Unit, Cardiff
}

SUMMARY The relationship between age-specific mortality rates and some indices of health facilities and some environmental and dietary factors has been studied in 18 developed countries. The indices of health care are not negatively associated with mortality, and there is a marked positive association between the prevalence of doctors and mortality in the younger age groups. No explanation of this doctor anomaly has so far been found. Gross national product per head is the principal variable which shows a consistently strong negative association with mortality.

Health services in developed countries, both state and private, are based upon many common assumptions about what constitutes adequate health care. Doctors and their paramedical colleagues in different developed countries receive similar educations to more or less the same standards, and their approaches to clinical and preventive medicine are unlikely to differ in fundamental principles. However, these countries show marked differences in their mortality rates and in health costs per head. In this paper, we seek to discover some factors to explain these differences in mortality.

\section{Materials and methods}

We employed the following criteria in selecting our countries:

1. Gross national product (GNP) exceeding $\$ 2000$ per caput. We made an exception for the Republic of Ireland (GNP $\$ 1949$ per caput).

2. Population of more than two million.

3. Data available for 1970 , but if not, data for 1969 or 1971 accepted if available.

4. We excluded countries where genetic factors may account for a substantial proportion of the difference in mortality between them and our other countries. This excluded Japan.

The data recorded on our countries are of two types: 'Input' and 'Output'. The input variables were selected according to two criteria: firstly, availability; and, secondly, an expectation that the variables might be related to the health of the communities. There are three types: health care indices, dietary consumption, and other demographic or economic variables. The output is measured by age-specific mortality rates up to the age of 64; we excluded the older ages because these are less likely to be associated with environmental factors.

The set of input variables is far too large in relation to the number of countries, and it was necessary to reduce the numbers to produce a more manageable set of relevant variables. This was accomplished by studying scatter diagrams of the mortality rates against each of the input factors, and by examining the correlation matrix of all the variables. Regression analysis of the output variables also helped to determine which variables may explain differences in mortality. Our criteria for the inclusion of factors in the subsequent analysis were:

1. The intrinsic importance of the variable; that is, we included variables such as prevalence of doctors, and availability of hospital beds, which many people consider to be self-evidently related to mortality.

2. A factor had to show a large product-moment correlation with at least one mortality rate, or it had to show a consistent pattern of association with several mortality rates.

3. A factor had to contribute a large proportion to the sums of squares of regression in a 
consistent manner in spite of changes in the composition of the other variables in the regression.

With only 18 countries, and many possible input variables, problems arise if we seek to apply standard methods of statistical inference, such as significance testing, to the data. If no allowance is made for multiple comparisons, then a correlation coefficient must exceed \pm 0.44 in order to be significantly different from zero at the $5 \%$ level of significance (assuming normality, etc.). It is arguable, however, that problems of statistical inference may not be relevant to our 18 countries because these cannot be regarded as being a random sample from some large set of developed countries. We think that there are so many possible sources of error in this sort of data, and so many pitfalls in interpretation, that a slavish adherence to significance testing, if relevant, would give our results a spurious and perhaps misleading aura of precision. We have used the criteria set out above in our analysis, and we have placed particular emphasis on the criterion of consistency. We believe that the results outlined in the next section are both interesting and amusing, and we make no apology for the necessarily subjective nature of some stages in our analysis.

\section{Results}

On the basis of the criteria listed earlier, we had a set of 18 countries which are shown in Table 1 .

Table 1 Countries used in the study

\begin{tabular}{ll}
\hline Australia & Republic of Ireland \\
Austria & Italy \\
Belgium & Netherlands \\
Canada & New Zealand \\
Denmark & Norway \\
England and Wales & Scotland \\
Finland & Sweden \\
France & Switzerland \\
German Federal Republic & United States of America \\
\hline
\end{tabular}

The input and output variables, their median values, and their ranges across the 18 countries, are shown in Tables 2 and 3.

The principal findings on examination of the raw correlations (Table 4) were as follows:

1. The correlation between prevalence of doctors and paediatricians and mortality is large and positive in the younger age groups, it is positive in young adult life, and it only becomes negative in the two oldest age groups.

2. The correlation between alcohol consumption and mortality shows a similar pattern to that for doctors, but with a particularly strong correlation between alcohol consumption and maternal mortality.
Table 2 Input variables

\begin{tabular}{|c|c|c|c|}
\hline & Minimum & Median & Maximum \\
\hline $\begin{array}{l}\text { HEALTH SERVICE INDICES } \\
\text { *Doctors } \\
\text { *Nurses } \\
\text { *Acute hospital beds } \\
\text { **Paediatricians } \\
\text { **Obstetricians } \\
\text { **Midwives } \\
\text { \% Gross National Product spent on }\end{array}$ & $\begin{array}{r}10 \cdot 2 \\
6 \cdot 7 \\
39 \cdot 5 \\
3.9 \\
12.6 \\
10 \cdot 2\end{array}$ & $\begin{array}{r}13 \cdot 7 \\
35.4 \\
52.3 \\
23.6 \\
27.3 \\
106.0\end{array}$ & $\begin{array}{r}18 \cdot 5 \\
56 \cdot 0 \\
97 \cdot 7 \\
68 \cdot 8 \\
50 \cdot 8 \\
399 \cdot 7\end{array}$ \\
\hline health & $4 \cdot 7$ & $5 \cdot 2$ & $7 \cdot 1$ \\
\hline $\begin{array}{l}\text { DIETARY INDICES } \\
\text { Cigarette consumption per caput } \\
\text { per annum } \\
\text { Alcohol consumption in litres per } \\
\text { caput per annum } \\
\text { Calories per caput per day } \\
\text { Grams protein per caput per day } \\
\text { Grams total fat per caput per day } \\
\text { Grams sugar per caput per day }\end{array}$ & $\begin{array}{r}630 \\
3 \cdot 7 \\
2805 \\
83 \cdot 9 \\
124 \cdot 3 \\
75 \cdot 8\end{array}$ & $\begin{array}{r}2440 \\
7 \cdot 2 \\
3195 \\
90 \cdot 5 \\
148 \cdot 3 \\
120 \cdot 0\end{array}$ & $\begin{array}{r}3810 \\
17 \cdot 5 \\
3410 \\
108 \cdot 2 \\
173 \cdot 8 \\
138 \cdot 5\end{array}$ \\
\hline $\begin{array}{l}\text { ECONOMIC AND } \\
\text { DEMOGRAPHIC FACTORS } \\
\text { Average population per km² } \\
\text { Gross National Product per caput } \\
\text { Education index } \\
\text { Intervention index ( } \% \text { of health } \\
\text { expenditure covered by public } \\
\text { expenditure) }\end{array}$ & $\begin{array}{c}1949 \cdot 6 \\
10 \cdot 0 \\
\text { c } \quad 40 \cdot 5\end{array}$ & $\begin{array}{r}77 \cdot 2 \\
4236 \\
16 \cdot 3\end{array}$ & $\begin{array}{r}324 \cdot 2 \\
6652 \\
49 \cdot 4\end{array}$ \\
\hline
\end{tabular}

Table 3 Output variables

\begin{tabular}{|c|c|c|c|}
\hline Mortality Rates & Minimum & Median & Maximum \\
\hline $\begin{array}{l}\text { Maternal per } 100000 \text { live births } \\
\text { Perinatal per } 1000 \text { live births } \\
\text { Infant per } 1000 \text { live births } \\
1-4 \text { years per } 10000 \text { population } \\
5-14 \text { years per } 10000 \text { population } \\
15-24 \text { years per } 10000 \text { population } \\
25-34 \text { years per } 10000 \text { population } \\
35-44 \text { years per } 10000 \text { population } \\
45-54 \text { years per } 10000 \text { population } \\
55-64 \text { years per } 10000 \text { population }\end{array}$ & $\begin{array}{r}8 \cdot 5 \\
16 \cdot 5 \\
11 \cdot 0 \\
5 \cdot 3 \\
3 \cdot 2 \\
6 \cdot 8 \\
8 \cdot 0 \\
16 \cdot 9 \\
43 \cdot 6 \\
107 \cdot 9\end{array}$ & $\begin{array}{r}21 \cdot 5 \\
22 \cdot 9 \\
18 \cdot 2 \\
8 \cdot 5 \\
4 \cdot 1 \\
8 \cdot 8 \\
10 \cdot 9 \\
22 \cdot 9 \\
56 \cdot 2 \\
150 \cdot 0\end{array}$ & $\begin{array}{r}54 \cdot 5 \\
31 \cdot 7 \\
29 \cdot 6 \\
10 \cdot 2 \\
4 \cdot 7 \\
13 \cdot 0 \\
15 \cdot 9 \\
32 \cdot 2 \\
72 \cdot 8 \\
183 \cdot 2\end{array}$ \\
\hline
\end{tabular}

3. The prevalence of nurses shows a negative association with maternal, perinatal, infant, and early childhood mortality. Their association with other mortality rates is positive or negligible.

4. The prevalence of acute hospital beds shows an erratic association with mortality rates; most of the associations are weak.

5. Cigarette consumption has a positive association with all the death rates, and this association is strongest in the two age groups $\mathbf{4 5}$ to54 and 55 to 64 .

6. The dietary factors, other than sugar consumption, have consistently positive associations with - mortality. In particular, total calorie intake and protein consumption are strongly positively associated with all mortality rates.

7. Sugar consumption has a large negative association with maternal mortality and with mortality in the younger age groups, and the association remains negative up to 44 years of age. 
Table 4 Correlation coefficients between the death rates and the input variables*

\begin{tabular}{|c|c|c|c|c|c|c|c|c|c|c|}
\hline \multirow[b]{3}{*}{$\begin{array}{l}\text { Doctors } \\
\text { Nurses } \\
\text { Beds } \\
\text { Paediatricians } \\
\text { Obstetricians } \\
\text { Midwives } \\
\text { \% GNP on health } \\
\text { Cigarettes } \\
\text { Alcohol } \\
\text { Calories } \\
\text { Protein } \\
\text { Fat } \\
\text { Sugar } \\
\text { Population density } \\
\text { GNP per caput } \\
\text { Education index } \\
\text { Intervention index }\end{array}$} & \multicolumn{10}{|c|}{ Mortality rates } \\
\hline & \multirow[b]{2}{*}{$\begin{array}{l}\text { Maternal } \\
0.45 \\
-0.39 \\
0.04 \\
0.40 \\
0.04 \\
-0.10 \\
-0.12 \\
0.17 \\
0.68 \\
0.41 \\
0.43 \\
0.10 \\
-0.61 \\
0.17 \\
-0.29 \\
-0.13 \\
-0.15\end{array}$} & \multirow[b]{2}{*}{$\begin{aligned} & \text { Perinatal } \\
& 0.60 \\
&-0.53 \\
&-0.32 \\
& 0.47 \\
& 0.18 \\
&-0.15 \\
& 0.01 \\
& 0.22 \\
& 0.52 \\
& 0.59 \\
& 0.37 \\
& 0.29 \\
&-0.57 \\
& 0.24 \\
&-0.48 \\
&-0.22 \\
& 0.15\end{aligned}$} & \multirow[b]{2}{*}{$\begin{array}{r}\text { Infant } \\
0.67 \\
-0.50 \\
-0.10 \\
0.51 \\
0.18 \\
-0.14 \\
-0.10 \\
0.22 \\
0.61 \\
0.58 \\
0.33 \\
0.23 \\
-0.56 \\
0.21 \\
-0.46 \\
-0.20 \\
-0.02\end{array}$} & \multicolumn{3}{|c|}{ Age groups (years) } & \multirow[b]{2}{*}{$\begin{array}{r}25-34 \\
0.23 \\
0.06 \\
0.06 \\
0.37 \\
0.54 \\
-0.28 \\
0.30 \\
0.35 \\
0.27 \\
0.30 \\
0.50 \\
0.37 \\
-0.20 \\
-0.35 \\
0.17 \\
-0.61 \\
0.48\end{array}$} & \multirow[b]{2}{*}{$\begin{array}{r}35-44 \\
0.04 \\
0.19 \\
-0.02 \\
0.15 \\
0.36 \\
0.00 \\
0.00 \\
0.32 \\
0.09 \\
0.31 \\
0.50 \\
0.21 \\
-0.05 \\
-0.45 \\
-0.13 \\
-0.47 \\
0.30\end{array}$} & \multirow[b]{2}{*}{$\begin{array}{r}45-54 \\
-0 \cdot 27 \\
0.27 \\
-0.14 \\
-0.11 \\
0.09 \\
0.26 \\
0.23 \\
0.46 \\
-0 \cdot 18 \\
0.38 \\
0.49 \\
0 \cdot 10 \\
0.26 \\
-0.30 \\
-0.36 \\
-0.27 \\
0.26\end{array}$} & \multirow[b]{2}{*}{$\begin{array}{r}55-6 \\
-0.20 \\
0.11 \\
-0.14 \\
-0.12 \\
0.04 \\
0.28 \\
0.36 \\
0.49 \\
-0.14 \\
0.52 \\
0.43 \\
0.16 \\
0.21 \\
-0.10 \\
-0.53 \\
-0.21 \\
0.07\end{array}$} \\
\hline & & & & $\begin{array}{r}1-4 \\
0.37 \\
-0.28 \\
0.07 \\
0.23 \\
-0.17 \\
-0.29 \\
-0.23 \\
0.11 \\
0.33 \\
0.58 \\
0.44 \\
0.32 \\
-0140 \\
0.07 \\
-0.41 \\
0.28 \\
-0.13\end{array}$ & $\begin{array}{r}5-14 \\
0.42 \\
0.37 \\
0.18 \\
0.31 \\
0.29 \\
-0.33 \\
0.27 \\
0.31 \\
0.32 \\
0.41 \\
0.20 \\
0.46 \\
-0.31 \\
-0.03 \\
0.18 \\
-0.43 \\
0.12\end{array}$ & $\begin{array}{r}15-24 \\
0.32 \\
0.12 \\
0.37 \\
0.35 \\
0.48 \\
-0.57 \\
0.39 \\
0.36 \\
0.26 \\
0.31 \\
0.47 \\
0.43 \\
-0.17 \\
-0.30 \\
0.25 \\
-0.79 \\
0.44\end{array}$ & & & & \\
\hline
\end{tabular}

*The input variables are defined in Table 2.

8. Gross national product per head is negatively associated with mortality except in the age groups 5 to 14 and 15 to 24 years.

9. The intervention index (per cent of health care provided by public funds) has a consistently negative association with all mortality rates, and these associations are large in the age groups 15 to 24 and 25 to 34 years. There is reason to believe, however, that in the 25 to 34 age group this correlation may be spurious, because the United States of America, with a high mortality rate and a low index, stands far away from the other countries, which appear to form a random cluster. Exclusion of the USA halves the correlation coefficient.

The correlations for smoking and for GNP per head accord with expectation, and lead us to suppose that our method of study gives sensible results. Many of the other results are confusing, and interpretation is made more difficult by the crosscorrelations among the input variables.

Regression analysis is a useful aid to sorting out the relationships between sets of moderately intercorrelated variables. There are too many input variables relative to the output variables to allow one large analysis, so we performed a series of regression analyses on various overlapping subsets of the input variables in order to seek a small subset, should it exist, of variables with the most explanatory power. The main findings from these analyses were:

1. None of the health service factors were consistently negatively related to mortality. Prevalence of doctors was positively associated with mortality in all age groups except 45 to 54 years, and the association was particularly marked for infant mortality, being even stronger than that suggested by the raw correlations.
2. The main factors consistently negatively associated with mortality were GNP per head, population density, sugar consumption, and the intervention index.

3. The principal factors, other than doctors, which were mainly positively associated with mortality were cigarette consumption and alcohol consumption.

4. Consumption of calories and protein showed very much weaker associations with mortality than their unadjusted correlations suggested, particularly when the regression equations contained GNP per head. The correlations of GNP with protein and of GNP with calorie consumption are -0.29 and -0.30 respectively. Gross national product per head appeared to have an independent association with the mortality rates over and above the association which may be attributed to its cross-correlation with the dietary variables. We therefore retained GNP per head and rejected protein and calorie consumption as contributing little additional explanatory power. Incidentally, total calorie intake and sugar consumption have a correlation coefficient of 0.02 , and the correlations between sugar consumption and fat and protein consumption are -0.12 and -0.04 respectively. It therefore follows that the contribution to the regression made by sugar consumption is unlikely merely to reflect a general dietary contribution.

On the basis of these analyses, we were able to select seven variables, each of which appeared to have some independent effect upon mortality in at least one age group. The set of variables as a whole had most of the explanatory power of our input data. The resulting regression equations seemed to be reasonably stable in the sense that adding other 
Table 5 Regression analysis of mortality rates on the seven variables with greatest explanatory power

\begin{tabular}{|c|c|c|c|c|c|c|c|c|}
\hline \multirow[t]{2}{*}{ Mortality rate } & \multicolumn{7}{|c|}{ Input variables } & \multirow[b]{2}{*}{$\begin{array}{l}\% \text { Total sums of } \\
\text { squares explained } \\
\text { by } 7 \text { variables }\end{array}$} \\
\hline & Doctors & GNP & Cigarettes & Alcohol & $\begin{array}{l}\text { Population } \\
\text { density }\end{array}$ & $\begin{array}{l}\text { Intervention } \\
\text { index }\end{array}$ & $\begin{array}{l}\text { Sugar } \\
\text { consumption }\end{array}$ & \\
\hline \multirow{2}{*}{$\begin{array}{l}\text { Maternal } \\
\text { Perinatal } \\
\text { Infant } \\
\text { Age groups (years) } \\
1-4 \\
5-14 \\
15-24 \\
25-34 \\
35-44 \\
45-54 \\
55-64 \\
\end{array}$} & $\begin{array}{c}1 \\
8^{*} \\
17^{*}\end{array}$ & $\begin{array}{l}-15 \\
-11^{*} \\
-16^{*}\end{array}$ & $\begin{array}{l}25 \\
8 * \\
10^{*}\end{array}$ & $\begin{array}{c}18 \\
0 \\
5^{*}\end{array}$ & $\begin{array}{r}-3 \\
0 \\
-2\end{array}$ & $\begin{array}{r}2 \\
-\quad 2 \\
0\end{array}$ & $\begin{array}{l}-29 \\
-8^{*} \\
-4\end{array}$ & $\begin{array}{l}72 \\
90 \\
97\end{array}$ \\
\hline & $\begin{array}{r}3 \\
1 \\
0 \\
-4 \\
-3 \\
-3 \\
-1 \\
\end{array}$ & $\begin{array}{c}-8 * \\
1 \\
0 \\
1 \\
-5 \\
-7 \\
-9 *\end{array}$ & $\begin{array}{l}1 \\
5 \\
2 \\
5 \\
4 \\
7 \\
7\end{array}$ & $\begin{array}{r}1 \\
-1 \\
0 \\
0 \\
-1 \\
-3 \\
-3\end{array}$ & $\begin{array}{l}1 \\
-2 \\
-7^{*} \\
-7 \\
-9^{*} \\
-4 \\
-1\end{array}$ & $\begin{array}{c}-6 \\
-2 \\
-16^{*} \\
-10^{*} \\
-9 \\
-4 \\
-3\end{array}$ & $\begin{array}{r}-5 \\
-6 \\
-8 \\
-11 \\
-8 \\
-3 \\
-3\end{array}$ & $\begin{array}{l}55 \\
42 \\
79 \\
65 \\
57 \\
55 \\
62\end{array}$ \\
\hline
\end{tabular}

The figures in the first seven columns are the percentage changes in the death rates following a one standard deviation increase in the input variables, the other input variables remaining fixed (see p. 202).

* $t$ value for inclusion of variable in regression exceeds 2 . Note, however, that even when not formally 'significant' the values given are best estimates.

variables singly, in turn, to the set of seven did not bring about major alterations in the first seven regression coefficients. Table 5 displays the results of regressing mortality rates on the chosen seven variables. The figures in the first seven columns are the percentage change in a given death rate (denoted by the row) for a 1 standard deviation increase in the input variable (denoted by the column) from its mean value, all other input variables being fixed at their mean values. This enables a comparison to be made, for example, between the effects of the prevalence of doctors, of maternal mortality, and of GNP, on the same mortality rate; or between the effect of prevalence of doctors on maternal mortality and that of GNP on infant mortality. The figures described above are not regression coefficients but they are derived from them. The legitimacy of the comparisons depends partly upon the stability of our regression equations over the input variables at our disposal and over others unknown to us, and partly on the fact that all the regression equations being compared have an identical set of independent (input) variables. The final column of Table 5 displays the percentage of the total (corrected) sums of squares of a given death rate explained by the set of seven variables.

The findings for infant mortality are particularly interesting. The seven variables explain $97 \%$ of the variance in infant mortality rates. In fact GNP per head alone explains $21 \%$ of the variance, while the prevalence of doctors alone explains $45 \%$ of the variance. Doctors and GNP per head together explain $82 \%$ of the variance. Doctors and GNP per head are not themselves highly correlated $(r=0 \cdot 2)$ in these developed countries.

Other points of interest in Table 5 are the positive association between alcohol consumption and maternal and infant mortality; the positive association between cigarette consumption and mortality, which is strongest with infant, perinatal, and maternal mortality, and is also strong in the two oldest age groups; and the negative association between population density and mortality in young adults. Gross national product is negatively associated with mortality in all age groups except 5 to 34 years, where it becomes negligible. Sugar consumption is negatively associated with mortality in all age groups. The intervention index becomes prominent in the age groups 15 to 24 and 25 to 34 years, although, as noted earlier, caution is required in interpreting it in the latter age group. Caution is also advisable in interpreting the results for maternal mortality, because this is a very uncommon cause of death in our 18 developed countries.

We repeated a similar correlation and regression analysis on a smaller set of variables based upon data in 1960. Our main findings from the 1970 data concerning GNP per head, doctors, and some other health care variables, were replicated on the 1960 data. Our analysis of the 1960 data, although cursory, does suggest that our findings are fairly stable over time and cannot too easily be dismissed as a chance curiosity.

\section{Discussion}

In the previous sections, we have remarked on the statistical difficulties associated with this study. We must now examine the broader issue of the general validity of studies which seek to draw inferences about the relationship between diet, environment, and mortality on the basis of a statistical comparison of countries.

The first objection to our study is that we have a highly selective collection of countries. This is indeed so, but this circumstance was forced upon us by the lack of developed countries for which extensive and reliable information was available. We may nevertheless claim the advantage that because our selected countries are all 'Western' or 
'European' in their styles of life and outlook, they may be expected to be fairly homogenous with respect to many variables which we have been unable to consider. A more serious methodological objection is that both the mortality rates and the input variables are averaged across each country, so that we cannot examine or allow for the undoubted heterogeneity of these factors within each country. We do not even have the comfort of knowing that their frequency distributions within each country are identical, and this throws greater doubt upon the representativeness of the simple averages. It may well be that these difficulties serve to dilute or underestimate any true associations, in which case any positive findings that we display are of enhanced interest. We cannot, however, dismiss the possibility that these problems cause entirely false associations. We do not claim that any of the associations are causal, although in one or two cases this hypothesis is attractive.

The striking relationship between the prevalence of doctors and mortality in the younger age groups deserves serious consideration. Stewart (1971), Hinds (1974), and Richardson (1976) have each commented on this association but have not found a totally convincing explanation. We have examined the possibility that this association could be explained in terms of other variables in our data set, but as Table 5 shows, we were unable to make the doctor anomaly go away. In spite of the possibility that there is some variable unknown to us which is cross-correlated with doctor prevalence and is capable of explaining the anomaly, we shall attempt a few explanatory hypotheses.

One possibility is that each country, consciously or unconsciously, adjusted the supply of doctors to meet the demand of medical problems. We attempted to test this by seeing whether the increase in the number of doctors between 1960 and 1970 was related to infant mortality in 1960 . No such relationship was found.

Another hypothesis is that increasing doctor prevalence increases 'dependency', but even Ivan Illich (1975) never suggested that the dependency was lethal. Similarly, 'iatrogenesis' might be suggested as a linking factor, but the wrong age groups are affected and the effect on mortality is too large.

Two factors suggest that the doctor and mortality relationship is not causal. Firstly, there is no evidence of a relationship between doctor prevalence and infant mortality rates when the regions of England and Wales are studied (West and Lowe, 1976). Secondly, the correlation and regression coefficients are still positive, but much weaker, if doctors are replaced by obstetricians and paedia- tricians, both of whom are likely to influence infant mortality more strongly than other doctors.

In general, however, we must admit defeat and leave it to others to extricate doctors from their unhappy position.

It is also difficult to explain the roles of population density and the intervention index (proportion of health service spending coming from government funds), both of which are strongly negatively associated with mortality in young adults. An interpretation of the effect of the intervention index is that the more nationalised the health services, the more effective is delivery of health care for potentially lethal illness. This may well be so, but in referring to our analysis, great caution is necessary before drawing this inference. Why should the intervention index be most strongly associated with deaths in young adults? A tentative explanation might be that deaths in young adults are primarily due to accidents, particularly road accidents, and non-fatal outcome following an accident may be dependent upon an efficient accident service. Private medicine would not be interested in funding an accident service which by its nature must often provide treatment before questions of fees are broached, and therefore this may be highly dependent upon public funding. If state financing of health services in developed countries is truly effective, however, then the intervention index should be strongly associated with other causes of death, particularly perinatal and infant mortality; and this we have not found. We originally thought that the population density effect could be explained by a negative association with road accidents but this is not so, and, in the light of other findings, we can hardly argue that nearness to medical help is important.

The results for gross national product per caput accord with expectations. Its association with mortality is strongest in the youngest and oldest age groups, and its negative sign is consistent with the idea that increasing overall wealth reduces mortality. In the intermediate age groups, its negligible association with mortality is consistent with the view that older children and young adults, having survived thus far, are little affected, with respect to mortality, by those social and environmental factors which correlate with wealth. This view is, of course, tenable only for societies in which overall wealth exceeds subsistence level, as is true of all our 18 developed countries.

It is not surprising that cigarette consumption should be associated with mortality rates in the older age groups. The strong association with infant and perinatal mortality is not easy to explain, although it is perhaps now generally recognised that smoking 
in pregnancy has a deleterious effect on the foetus but we cannot claim to have shown this.

Our finding that sugar consumption is not positively associated with mortality is inconsistent with the belief that unrefined sugar is generally harmful, and associated with coronary heart disease in particular (Yudkin, 1957). We would not, however, wish to place too much weight upon our own findings. In any case, severe doubts about the harmful role of sugar have been raised by other workers in studies designed to test this issue (Bennett et al., 1970; MRC Working Party, 1970).

We believe that one overall conclusion may be drawn from this study. It is that health service factors are relatively unimportant in explaining the differences in mortality between our 18 developed countries. There is nothing new in this. The case has been argued particularly well by Fuchs (1974). As a corollary to this, it could also be argued that there is probably a considerable element of inefficiency in the way some developed countries spend so much more than others on health services. As to the overall value of the results, we consider them to be interesting and provocative, and perhaps capable of generating worthwhile new hypotheses which may be tested in appropriate studies.

We thank Robert Maxwell and many international organisations for help with this study.

\section{Appendix}

\section{SOURCES OF DATA AND INDICES}

Mortality data and population density data

Doctors, nurses, and beds per 10000 population

\section{Alcohol (litres per} head per year)

\footnotetext{
Manufactured cigarettes per adult (aged over 15) per annum
}

World Health Organisation (1973). World Health Statistics Annual. Vol. 1. Vital Statistics and Causes of Death for 1970. WHO: Geneva.

World Health Organisation (1973). World Health Statistics Annual. Vol. 3. Statistics of Health Personnel, etc. WHO: Geneva. (With help from Dr. Robert Maxwell).

Produkschap voor Gedistilleerde Dranken (1975). Hoeveel alcoholhoudende dranken worden er in de wereld gedronken? Schiedam, Netherlands.

Tobacco Research Council (1972). Tobacco Consumption in various countries. Tobacco Research Council: London
Reprints from A. L. Cochrane, Rhoose Farm House, Rhoose, South Glamorgan.

\section{References}

Bennett, A. E., Doll, R., and Howell, R. W. (1970). Sugar consumption and cigarette smoking. Lancet, 1 , 1011-1014.

Fuchs, V. R. (1974). Who shall live? Basic Books: New York.

Hinds, M. W. (1974). Letter. New England Journal of Medicine, 291, 741.

Illich, I. (1975). Medical Nemesis-the Expropriation of Health. Calder and Boyars: London.

Medical Research Council. Working Party on the relationship between dietary sugar intake and arterial disease (1970). Lancet, 2, 1265-1271.

Richardson, J. (1976). The Dependency HypothesisThat more doctors will result in lower quality health. Research paper No. 113, School of Economics and Financial Studies. Macquarie University: Sydney.

Stewart, C. T. (1971). Allocation of resources to health. Journal of Human Resources, 6(1), 103-122.

West, R. R., and Lowe, C. R. (1976). Regional variations in need for and provision and use of child health services in England and Wales. British Medical Journal, 2, 843-846.

Yudkin, J. (1957). Diet and coronary thrombosis. Lancet, 2, 155-162.
GNP per head (we used data for 1960 and 1970 at constant 1973 prices as we hope to study changes later)

$\%$ GNP spent on health United Nations Year Book of

Percentage of health expenditure covered by public expenditure (intervention index)

Education index. 'Percentage of the cohort continuing education after age 18' (both sexes)

Dietary data National Accounts.

Statistics for 1970. Office of Health Economics: London.

Dr. Robert Maxwell.

International Bank for Reconstruction and Development, Washington. (Through the kindness of Dr. Schrieber, 1977).

OECD Paris Working Party on Economic Policy (through the kindness of Dr. J. P. Poullier).

UNESCO, Paris (through the kindness of Dr. S. Fauchette).

OECD (1975). Food consumption statistics 1955-1973. OECD: Paris. 
Journal of Epidemiology and Community Health, 1979, 33, 307

To the Editor, Journal of Epidemiology and Community Health

\section{The doctor anomaly}

SIR-Dr. Cochrane and his colleagues have sought, by ingenious methods, to get rid of the positive correlation between infant mortality and physician supply in 18 developed countries (Cochrane et al., 1978). They say '. . . . we must admit defeat and leave it to others to extricate doctors from their unhappy position'. This remark has had the intended effect of challenging the reader.

It occurrred to us that some of the countries richly endowed with physicians may obtain their large supplies by having bigger medical schools, larger classes, and thus less individual instruction of the medical student. The consequence could be a poorer standard of medical practice, the influence of which would be evident in the mortality of the younger age groups where the outcome of disease is most susceptible to the physician's skill. Another possible indicator of the quality of medical education would be the proportion of a country's graduates passing the United States licensing examination for foreign medical graduates. This would be a legitimate indicator for our purpose if the quality of emigrating physicians bears the same relationship to the quality of indigenous physicians in all the countries under study.

We have obtained data on class size in the first year of medicine and on the percentage of candidates passing the ECFMG examination in the United States for 15 of the 18 countries studied by Cochrane et al. (Canada and the US graduates do not take the ECFMG, and Scotland was combined with England for class size). Data on class size came from the World
Health Organisation (1973) and data on the ECFMG from the US Health Resources Administration (1974).

In these 15 countries, the zero-order correlation of infant mortality with physicians per 10000 population is $+0 \cdot 67$, almost identical to that found for the 18 countries. The partial correlation resulting from the introduction of the two variables, class size and examination performance, is only $+0 \cdot 39$. The matrix of the zero-order correlations show why this has happened.

$\begin{array}{lccc} & \begin{array}{c}\text { Physician } \\ \text { supply }\end{array} & \begin{array}{c}\text { Average } \\ \text { class size }\end{array} & \begin{array}{c}\text { \% passing } \\ \text { ECFMG }\end{array} \\ & (1970) & (1970) & (1970-72) \\ \text { Infant mortality (1970) } & +0.67 & +0.57 & -0.71 \\ \text { Physician supply } & & +0.68 & -0.62 \\ \text { Class size } & & & -0.68\end{array}$

While we have not 'made the doctor anomaly go away', we have substantially reduced its size. Perhaps other readers may be able to whittle it down further.
Department of Epidemiology and Preventive Medicine,

University of Western Ontario, Kresge Building,

London, Canada N6A $5 B 7$.
CAROL BUCK

Professor of Epidemiology

VIOLET BACSI

Research Assistant

\section{References}

Cochrane, A. L., St. Leger, A. S., and Moore, F. (1978). Health service 'input' and mortality 'output' in developed countries. Journal of Epidemiology and Community Health, 32, 200-205.

World Health Organisation (1973). World Directory of Medical Schools 1970. WHO: Geneva.

US Health Resources Administration (1974). Foreign medical graduates and physician manpower in the United States. DHEW Publication HRA 74-30. Appendix Table 8.

\section{Correction}

Cochrane, A. L., St. Leger, A. S., and Moore, F. (1978). Health service 'input' and mortality 'output' in developed countries. Journal of Epidemiology and Community Health, 32, 200-205.

In Table 4 the last two row headings 'Education index' and 'Intervention index' should be transposed. The correlation coefficient between intervention index and mortality at age 1-4 years should read $-0 \cdot 28$. The text and conclusions are not affected. 